\title{
Krill-derived Phospholipids Rich in n-3 Fatty Acid Improve Spatial Memory in Adult Rats
}

\author{
Shuji Gamoh \\ Department of Environmental Physiology \\ Shimane University Faculty of Medicine, Izumo, Japan \\ $\&$ \\ Laboratory of Lipid Nutrition \\ Kyushu University of Health and Welfare School of Pharmaceutical Sciences \\ Nobeoka, Japan \\ Michio Hashimoto (Corresponding author) \\ Department of Environmental Physiology \\ Shimane University Faculty of Medicine, Izumo, Japan \\ Tel: 81-853-20-2112 E-mail: michio1@med.shimane-u.ac.jp \\ Kenichi Yanagimoto \\ Human Life Science R\&D Center \\ Nippon Suisan Kaisha, Ltd. Chiyoda-ku, Tokyo, Japan \\ Masanori Katakura, Haque Md Abdul \& Osamu Shido \\ Department of Environmental Physiology \\ Shimane University Faculty of Medicine, Izumo, Japan
}

Received: January 27, 2011

Accepted: February 11, 2011 Published: December 1, 2011

doi:10.5539/jas.v3n4p3

URL: http://dx.doi.org/10.5539/jas.v3n4p3

\begin{abstract}
We indicated previously that dietary supplementation of the ethyl ester form of eicosapentaenoic acid (EPA) and docosahexaenoic acid (DHA) improves spatial cognition through an increase in DHA levels in the hippocampus and cerebral cortex. In the present study, we investigated the effects of peroral administration of krill-derived phospholipids (KPL) on the spatial learning ability and the fatty acid composition of the plasma and brain tissues. Both parameters of the radial arm maze task, the reference- and working memory errors, significantly decreased after KPL administration. The plasma and brain levels of n-3 PUFAs significantly increased, and the levels of arachidonic acid were significantly decreased after KPL administration. Lipid peroxidation in the plasma and in brain tissues was depressed, and cell generation in the dentate gyrus was enhanced in KPL-administered rats. All these effects are similar to those induced by the ethyl ester forms of EPA and DHA.
\end{abstract}

Keywords: Krill-derived phospholipids, Docosahexaenoic acid, Eicosapentaenoic acid, Spatial memory, Antioxidative defens

\section{Introduction}

The beneficial effects of dietary intake of n-3 polyunsaturated fatty acids (PUFAs) on the maintenance of good health are well known. The most bioactive and well-investigated n-3 PUFAs are eicosapentaenoic acid (C20:5n-3, EPA) and docosahexaenoic acid (C22:6n-3, DHA). Recently, growing evidence suggests that n-3 PUFAs maintain and enhance central nervous system (CNS) functiuon, including learning and memory. We reported that chronic administration of DHA improves the learning ability both in young (5 weeks old) (Gamoh 
et al., 1999) and in aged (100 weeks old) rats (Gamoh et al., 2001). We have also reported that DHA administration promotes the neurogenesis in the granule cell layer of the dentate gyrus in adult rats (Kawakita et al., 2006). Newly generated neurons in the hippocampal formation may be associated with the ability of learning and memory (Song et al., 2002, Schmidt-Hieber et al., 2004). In our recent study, EPA (Hashimoto et al., 2009) or DHA (Hashimoto et al., 2005, Hashimoto et al., 2002) exerted protective effects against impairment of spatial learning cognition induced by infusion of amyloid $\beta_{(1-40)}$. All of our previous studies were carried out using highly purified (>95\%) n-3 PUFA ethyl esters. Recently, however, more attention has been drawn to the differences between fatty acid formulations with regard to ingestion, absorption, and/or efficacy (Dyerberg et al., 2010).

Certain marine fish contain substantial amounts of EPA and DHA, and this is the reason for the use of fish oil as a dietary source of n-3 PUFAs and as the raw materials for EPA preparations. Fish oil typically contains n-3 PUFAs in the triglyceride form or as fatty acid ethyl esters (Harris et al., 1988). During the process of EPA purification, triglycerides are converted to ethyl esters; therefore, commercial highly purified EPA preparations contain EPA in the ethyl esters. Antarctic krill, also known as Euphausia superba, is a shrimp-like crustacean that is rich in both EPA and DHA. Krill oil differs from fish oil in that it contains a relatively high amount of n-3 PUFAs as phospholipids. In the present study, we assessed whether krill-derived phospholipid (KPL) administration can increase the n-3 PUFAs content of the plasma and the brain tissues, and can improve spatial cognition through cell generation in the dentate gyrus of the hippocampus.

\section{Materials and Methods}

\subsection{Animals and diet}

All rats were handled and killed in accordance with the procedures outlined in the Guidelines for Animal Experimentation of Shimane University (Shimane, Japan) as compiled from the Guidelines for the Animal Experimentation of the Japanese Association for Laboratory of Animal Science. Wistar rats (Jcl: Wistar) purchased from CLEA Japan (Osaka, Japan) were housed in a room under controlled temperature $\left(23 \pm 2^{\circ} \mathrm{C}\right)$, humidity (50 $\pm 10 \%$ ) and a light-dark cycle (light: 08:00-20:00; dark 20:00-08:00). They were provided with a fish-oil-deficient diet (F-1 TM; Funabashi Farm, Funabashi, Japan) (Table 1) and water ad libitum. Inbred second-generation male rats, fed the same F-1 diet, were used for our study.

KPL was obtained from Nippon Suisan Kaisha, Ltd. (Tokyo, Japan). KPL was weighed and emulsified daily in twice of its volume of sterilized water. The fatty acid composition of the KPL emulsion is shown in Table 2. Rats were divided into 3 groups: high-dose (HD; 300 mg EPA and 120 mg DHA), low-dose (LD; 215 mg EPA and $86 \mathrm{mg}$ DHA), and the control group that received sterilized water only.

\subsection{Radial maze task}

Three weeks after the start of KPL administration, each rat was placed on a maze-task schedule and the spatial memory-related learning ability was assessed as described previously (Gamoh et al., 1999). In brief, the rats maintained on the food deprivation schedule were trained to acquire a reward pellet at the end of only 4 arms of an 8 -arm radial maze. The performance involved 2 parameters of learning ability, namely, reference memory error (RME, entry into an unbaited arm); and working memory error (WME, entry into arm which had already visited within the trial). Each rat was given 2 daily trials, 6 days/week for a total of 3 weeks.

\subsection{Sample preparation}

After the maze tasks were completed, the rats were anesthetized with sodium pentobarbital $(65 \mathrm{mg} / \mathrm{kg}$ body weight [BW], i.p.) to obtain blood, cerebral cortex and hippocampus as previously described (Hashimoto et al., 2009). A portion of the brain tissues was immediately homogenized in 10 times its volume of ice-cold 0.32 $\mathrm{mol} / \mathrm{L}$ sucrose buffer ( $\mathrm{pH}$ 7.4) containing $2 \mathrm{mmol} / \mathrm{L}$ EDTA, $0.5 \mathrm{mg} / \mathrm{L}$ leupeptin, $0.5 \mathrm{mg} / \mathrm{L}$ pepstatin, $0.5 \mathrm{mg} / \mathrm{L}$ aprotinin, and $0.2 \mathrm{mmol} / \mathrm{L}$ phenylmethylsulfonyl fluoride using a Polytron homogenizer (PCU 2-110; Kinematica). The residual tissues were flash frozen in liquid $\mathrm{N}_{2}$ and stored at $-80^{\circ} \mathrm{C}$ until use.

\subsection{Analysis of fatty acid profiles and oxidative status}

The fatty acid profiles of the plasma and brain tissues were determined by gas chromatography as described previously (Gamoh et al., 1999).

Lipid peroxide (LPO) was assessed by the thiobarbituric acid-reactive species assay as described previously (Hashimoto et al., 2005). The LPO levels were indicated as $\mathrm{nmol} / \mathrm{L}$ of malondialdehyde, and were calculated relative to a standard preparation of 1,1,3,3-tetraethoxypropane, per milligram of protein. The protein concentration was estimated by the method of Lowry et al. (Lowry et al., 1951). 
The levels of reactive oxygen species (ROS) were determined as described (Hashimoto et al., 2005, Hashimoto et al., 2002). In brief, $50 \mu \mathrm{L}$ of freshly prepared brain tissue homogenate were mixed with $4.85 \mathrm{~mL}$ of 100 $\mathrm{mmol} / \mathrm{L}$ potassium phosphate buffer $(\mathrm{pH} 7.4)$ and incubated with $2^{\prime}-7^{\prime}$-dichlorofluorescein diacetate in methanol at a final concentration of $5 \mathrm{mmol} / \mathrm{L}$ for $15 \mathrm{~min}$ at $37^{\circ} \mathrm{C}$. The dye-loaded samples were centrifuged at $12,500 \times \mathrm{g}$ for $10 \mathrm{~min}$ at $4^{\circ} \mathrm{C}$. The pellet was mixed on a vortex at $0^{\circ} \mathrm{C}$ in $5 \mathrm{~mL}$ of $100 \mathrm{mmol} / \mathrm{L}$ potassium phosphate buffer (pH 7.4) and incubated for $60 \mathrm{~min}$ at $37^{\circ} \mathrm{C}$. Fluorescence was measured with a Hitachi 850 spectrofluorometer at wavelengths of $488 \mathrm{~nm}$ for excitation and $525 \mathrm{~nm}$ for emission. The cuvette holder was maintained at $37^{\circ} \mathrm{C}$. ROS were quantified from a dichlorofluorescein standard curve in methanol.

\subsection{BrdU injection and immunohistochemical analysis}

A sub group of rats, selected at random, of $\mathrm{HD}(n=4)$ and control $(n=3)$ groups received 1 daily i.p. injection $(50 \mathrm{mg} / \mathrm{kg}$ ) of 5-bromo-2'-deoxyuridine (BrdU) for 5 days. Three days after the last BrdU injection, the rats were anesthetized with sodium pentobarbital $(65 \mathrm{mg} / \mathrm{kg}$ BW, i.p.). After blood sample collection, the rats were perfused transcardially with PBS (-) and fixed with $4 \%$ formaldehyde. The brains were removed and post-fixed for $24 \mathrm{~h}$ in $4 \%$ formaldehyde, which was then replaced by $25 \%$ sucrose in PBS (-). Coronal sections (40 $\mu \mathrm{m})$ were cut out and subjected to immunohistochemical analysis as described previously (Kawakita et al., 2006).

\subsection{Statistical analysis}

Results are expressed as mean \pm SEM. Behavioral data were analyzed by two-way ANOVA followed by Fisher's PLSD for post-hoc comparisons. All other parameters were analyzed by one-way ANOVA with Bonferroni multiple comparison tests. $P<0.05$ was considered statistically significant. The statistical programs used were GB-STAT 6.5.4 (DynamicMicrosystems) and StatView 4.01 (MindVision Software, Abacus Concepts). A level of $P<0.05$ was considered significant.

\section{Results}

\subsection{Effect of KPL on the fatty acid profiles of the plasma}

The plasma concentration of EPA significantly increased and arachidonic acid (AA) significantly decreased in a dose-dependent manner after KPL administration (Table 3). The plasma concentrations of docosapentaenoic acid (C22:5n-3, DPA) and DHA were also significantly increased, but the changes were not dose-dependent.

\subsection{Effect of KPL on the fatty acid profiles of the brain tissues}

The fatty acid profiles of the brain tissues are shown in Table 4. The levels of EPA, DPA, and DHA both in the cerebral cortex and the hippocampus significantly increased and AA significantly decreased after KPL administration. Therefore, the ratios of DHA/AA and $n-3 / n-6$ were significantly raised by KPL administration in a dose-dependent manner.

\subsection{Effect of KPL on the radial-maze score}

The effects of KPL administration on 2 parameters of the radial-arm maze performance, RME and WME, are shown in Fig 1A and 1B, respectively. The score is expressed as the mean number of RME and WME for each group, with data averaged over blocks of 6 trials.

Randomized 2-factor (block and group) ANOVA identified significant main effects of both blocks $(P<0.0001)$ and groups $(P<0.0001)$ on the number of RMEs, with a significant Block $\times$ Group interaction $(P<0.0001)$. On the other hand, ANOVA identified significant main effects of both blocks $(P<0.0001)$ and groups $(P<0.0001)$ on the number of WMEs, without a significant Block $\times$ Group interaction $(P=0.1965)$.

\subsection{Effect of KPL on the oxidative status}

The plasma LPO levels significantly decreased after KPL administration (Fig 2). The levels of LPO in both the cerebral cortex and hippocampus also significantly decreased after the administration (Fig 3A). The levels of ROS were significantly low in both the cerebral cortex and hippocampus of KPL-administered rats (Fig 3B).

\subsection{Effect of KPL on cell generation in the dentate gyrus of the hippocampus}

To examine whether cell generation in the dentate gyrus of the hippocampus can be accelerated by KPL administration, the dividing cells were labeled with BrdU and were visualized using specific antibodies for BrdU. The number of $\mathrm{BrdU}(+)$ cells per unit volume of the granule cell layer increased significantly after KPL administration (Fig 4).

\section{Discussion}

The objective of this study was to confirm the effect of peroral administration of KPL which contains relatively 
high amount of EPA and DHA as phospholipids on the fatty acid profiles of the plasma and brain tissues and on spatial learning. Both numbers of RME and WME were significantly decreased by KPL administration, but no significant differences were observed in the score of the maze task between the LD and HD groups. In addition, even a lower dose of KPL (EPA + DHA $=100 \mathrm{mg} / \mathrm{kg}$ ) could neither affect the DHA levels in brain tissues nor the learning ability (data not shown). Judging from these results, the optimum dose of KPL is still unclear, but the dose for the LD group (EPA + DHA $=300 \mathrm{mg} / \mathrm{kg}$ ) is sufficient to improve spatial learning cognition (Fig 1). Learning ability is associated with brain acetylcholine levels, which are increased by the dietary supplementation of DHA (Minami et al., 1997). Furthermore, dietary intake of both DHA-rich egg phospholipids and tuna oil increased the maximum acetylcholine release from rat hippocampus by increasing the levels of hippocampal DHA. These effects are only correlated with the dose of DHA but not with the form of administered lipid (Aïd et al., 2005). We have indicated that a low dose of KPL (EPA + DHA $=300 \mathrm{mg} / \mathrm{kg}$ ), $300 \mathrm{mg} / \mathrm{kg}$ of EPA ethyl esters (Hashimoto et al., 2009) and $300 \mathrm{mg} / \mathrm{kg}$ of DHA ethyl esters (Hashimoto et al., 2005) have similar effects on the spatial learning ability. These results suggest the possibility that supplementation of not only DHA but also EPA improves the spatial learning ability through stimulation of acetylcholine release from rat hippocampus. Alternatively, administered EPA may be promptly converted to DHA.

Next, we investigated the levels of n-3 PUFAs in the plasma and brain tissues.

Plasma levels of EPA and DHA were markedly increased and AA levels were dramatically decreased by KPL administration (Table 3). These changes were greater than those observed after administration of comparable amounts of the ethyl ester forms of EPA or DHA as shown in our previous studies (Gamoh et al., 1999, Hashimoto et al., 2009, Hashimoto et al., 2005). DHA from phosphatidylcholine is easily incorporated into the brain tissues (Lim and Suzuki, 2008). The krill-derived phospholipids used in this study, consists primary of phosphatidylcholine ( $80 \%$ of total lipids). Therefore, n-3 PUFAs from phospholipids may be more easily absorbable than those in the ethyl ester form. These results partly advocate the study by Maki et al (2009). In this previous study, krill (216 mg/d EPA and $90 \mathrm{mg} / \mathrm{d}$ DHA) or menhaden oil (212 mg/d EPA and $178 \mathrm{mg} / \mathrm{d}$ DHA) was administered to healthy human subjects, and the results showed that the plasma levels of EPA and DHA were significantly increased in both krill- and menhaden oil-administered groups compared to the control (olive oil-administered) group. The authors indicated that the increment of the plasma EPA levels in the krill oil-administered group was slightly higher than in the menhaden oil-administered group; however, the increment in the plasma DHA levels was completely dependent on the dose of DHA, regardless of the type of oil. Although, we cannot clearly account for the differences between their data and ours at present, these disparities might be caused by differences in the species or the doses used.

The changes in the fatty acid composition of the cerebral cortex and hippocampus (Table 4) were also greater in the KPL-administered rats than in ethyl ester-administered rats (Hashimoto et al., 2009, Hashimoto et al., 2005). Therefore, the fatty acid composition of the brain tissue may be affected by fatty acids in the plasma. Interestingly, the levels of DPA in either the plasma or in the brain tissues were the most susceptible to the form of administered lipids (changes in DPA induced by DHA ethyl ester administration were shown in Ref 7, but those induced by EPA ethyl ester administration have not previously been shown). In particular, 6-fold (LD) or 8 -fold (HD) increases in the DPA concentration in the hippocampus were observed compared to the control. The elevated DPA may be a metabolite of administered EPA (and/or DHA) in KPL, because the concentration of DPA in KPL was low (Table 2). These results suggest that administered EPA from phospholipids may be promptly converted to DHA through DPA before the learning ability is affected. Furthermore, EPA is more easily metabolized to DHA in the hippocampus than in the cerebral cortex.

We have previously suggested that the antioxidative effect of n-3 PUFAs is related to the improvement of the spatial learning ability (Gamoh et al., 2001, Hashimoto et al., 2009, Hashimoto et al., 2005, Hashimoto et al., 2002, Hossain et al., 1999). Consequently, we investigated the oxidative levels in the plasma and brain tissues. Lipid peroxidation in the plasma significantly decreased in the KPL-administered groups compared to the control group (Fig 2). The levels of LPO and ROS in the cerebral cortex and the hippocampus in both the HD and LD groups were also significantly decreased compared to the control, but significant differences between the HD and LD groups were not observed (Fig 2). Engström et al. suggested that the plasma levels of LPO remains unaltered in rats fed a diet supplemented with EPA- or DHA-rich fish oil in comparison with standard diet-fed rats (Engström et al., 2009). Moreover, in our present study, administration of the ethyl ester form of EPA and DHA significantly decreased the LPO levels in either the cerebral cortex or the hippocampus in aged (100 weeks old) rats (Gamoh et al., 2001), but in young-adult rats (Hashimoto et al., 2009, Hashimoto et al., 2005). Further investigations are needed to clarify these contradictions; however, those may be caused by the differences of administered lipid forms. 
Most neurons in mammalian brains are generated during embryonic periods; however, new neurons are generated by neural stem cells throughout life in the dentate gyrus of the hippocampus (Eriksson et al., 1998). Newly generated mature neurons may be recruited into patterns of new memory networks (Kee et al., 2007). On the other hand, immature granule cells may play distinct roles in hippocampal-dependent memory formation (Aimone et al., 2006). We have reported that chronic administration of DHA ethyl esters enhanced neurogenesis in the granule cell layer in the hippocampus (Kawakita et al., 2006). Most recently, we have indicated that DHA enhances neuronal differentiation of neural stem cells by controlling the expression levels of basic helix-loop-helix transcription factors (Katakura et al., 2009). In the present study, KPL administration significantly enhanced cell generation in the granule cell layer of the dentate gyrus (Fig 3); however, we did not investigate whether the newly generated cells differentiate into mature neurons. Moreover, whether administration of EPA ethyl esters can enhance neurogenesis in the dentate gyrus remains to be elucidated.

Regarding the effects of n-3 PUFAs on brain functions, most studies have focused on DHA. However, there are few but interesting reports on the effects of EPA on the cognitive learning ability. Song and Horrobin reported that chronic administration of EPA (ethyl ester) attenuates memory impairment induced by interleukin-1 $\beta$ administration (Song and Horrobin, 2004). Recently, it was reported that age-related decreases in the levels of nuclear receptors, for example, retinoid $\mathrm{X}$ receptors or retinoic acid receptors, were reversed by supplementation of EPA and DHA in rats. Interestingly, these reversals appear only partial in rats supplemented with DHA alone (Dyall et al., 2010). These reports suggest that ingestion of both EPA and DHA is more effective than ingestion of DHA alone for the maintenance of CNS functions. Therefore, KPL, which contains a mixture of EPA and DHA at a ratio of 5:2, is more advantageous than the ethyl ester form of EPA or DHA alone for brain functions.

\section{Conclusion}

Chronic administration of KPL improves spatial-memory related learning ability in the similar way as ethyl ester form of EPA or DHA. Until now, krill has not received much attention as a health food. Nonethless, krill is a good source of high-quality protein and n-3 PUFAs; therefore, it may become an important source of nutrition in the future.

\section{References}

Aimone, J. B., Wiles, J. \& Gage, F. H. (2006). Potential role for adult neurogenesis in the encoding of time in new memories. Nature Neuroscience, 9, 723-727. http://dx.doi.org/10.1038/nn1707

Aïd, S., Vancassel, S., Linard, A., Lavialle, M. \& Guesnet, P. (2005). Dietary docosahexaenoic acid [22: 6(n-3)] as a phospholipid or a triglyceride enhances the potassium chloride-evoked release of acetylcholine in rat hippocampus. Journal of Nutrition, 135, 1008-1013.

Dyall, S. C., Michael, G. J. \& Michael-Titus, A. T. (2010). Omega-3 fatty acids reverse age-related decreases in nuclear receptors and increase neurogenesis in old rats. The Journal of Neuroscience Research, 88, 2091-2102. http://dx.doi.org/10.1002/jnr.22390

Dyerberg, J., Madsen, P., Møller, J. M., Aardestrup, I. \& Schmidt, E. B. (2010). Bioavailability of marine n-3 fatty acid formulations. Prostaglandins, Leukotriens and Essential Fatty Acids, 83, 137-141. http://dx.doi.org/10.1016/j.plefa.2010.06.007

Engström, K., Saldeen, A. S., Yang, B., Mehta, J. L. \& Saldeen, T. (2009). Effect of fish oils containing different amounts of EPA, DHA, and antioxidants on plasma and brain fatty acids and brain nitric oxide synthase activity in rats. Upsala Journal of Medical Sciences, 114, 206-213. http://dx.doi.org/10.3109/03009730903268958

Eriksson, P. S., Perfilieva, E., Björk-Eriksson T., Alborn, A. M., Nordborg, C., Peterson, D. A. \& Gage, F. H. (1998). Neurogenesis in the adult human hippocampus. Nature Medicine, 4, 1313-1317. http://dx.doi.org/10.1038/3305

Gamoh, S., Hashimoto, M., Sugioka, K., Hossain, M. S., Hata, N., Misawa, Y. \& Masumura, S. (1999). Chronic administration of docosahexaenoic acid improves reference memory-related learning ability in young rats. Neoroscience, 93, 237-241. http://dx.doi.org/10.1016/S0306-4522(99)00107-4

Gamoh, S., Hashimoto, M., Hossain, S. \& Masumura, S. (2001). Chronic administration of docosahexaenoic acid improves the performance of radial arm maze task in aged rats. Clinical Experiment of Pharmacology and Physiology, 28, 266-270. http://dx.doi.org/10.1046/j.1440-1681.2001.03437.x

Harris, W. S., Zucker, M. L. \& Dujovne, C. A. (1988). Omega-3 fatty acids in hypertriglyceridemic patients: triglycerides vs. methyl esters. American Journal of Clinical Nutrition, 48, 992-997.

Hashimoto, M., Hossain, S., Shimada, T., Sugioka, K., Yamasaki, H., Fujii, Y., Ishibashi, Y., Oka, J. \& Shido, O. 
(2002). Docosahexaenoic acid provides protection from impairment of learning ability in Alzheimer's disease model rats. Journal of Neurochemistry, 81, 1084-1091. http://dx.doi.org/10.1046/j.1471-4159.2002.00905.x

Hashimoto, M., Tanabe, Y., Fujii, Y., Kikuta, T. Shibata, H. \& Shido, O. (2005). Chronic administration of docosahexaenoic acid ameliorates the impairment of spatial cognition learning ability in amyloid beta-infused rats. Journal of Nutrition, 135, 549-555.

Hashimoto, M., Hossain, S., Tanabe, Y., Kawashima, A., Harada, T., Yano, T., Mizuguchi, K. \& Shido, O. (2009). The protective effect of dietary eicosapentaenoic acid against impairment of spatial cognition learning ability in rats infused with amyloid (1-40). The Journal of Nutritional Biochemistry, 20, 965-973. http://dx.doi.org/10.1016/j.jnutbio.2008.08.009

Hossain, M. S., Hashimoto, M., Gamoh, S., \& Masumura, S. (1999). Antioxidative effects of docosahexaenoic acid in the cerebrum versus cerebellum and brainstem of aged hypercholesterolemic rats. Journal of Neurochemistry, 72, 1133-1138. http://dx.doi.org/10.1046/j.1471-4159.1999.0721133.x

Katakura, M., Hashimoto, M., Shahdat, H. M., Gamoh, S., Okui, T., Matsuzaki, K. \& Shido, O (2009). Docosahexaenoic acid promotes neuronal differentiation by regulating basic helix-loop-helix transcription factors and cell cycle in neural stem cells. Neuroscience, 160, 651-660. http://dx.doi.org/10.1016/j.neuroscience.2009.02.057

Kawakita, E., Hashimoto, M. \& Shido, O. (2006). Docosahexaenoic acid promotes neurogenesis in vitro and in vivo. Neuroscience, 139, 991-997. http://dx.doi.org/10.1016/j.neuroscience.2006.01.021

Kee, N., Teixeira, C. M., Wang, A. H. \& Frankland, P. W. (2007). Preferential incorporation of adult-generated granule cells into spatial memory networks in the dentate gyrus. Nature Neuroscience, 10, 355-362. http://dx.doi.org/10.1038/nn1847

Lim, S.Y. \& Suzuki, H. (2008). Dietary phosphatidylcholine improves maze-learning performance in adult mice. Journal of Medicinal Food, 11, 86-90. http://dx.doi.org/10.1089/jmf.2007.060

Lowry, O. H. Rosebrough, N. J. Farr, A. L. \& Randall, A. L. (1951). Protein measurement with the folin phenol reagent. The Journal of Biological Chemistry, 193, 265-275.

Maki, K. C., Reeves, M. S., Farmer, M., Griinari M., Berge, K., Vik, H., Hubacher, R. \& Rains, T. M. (2009). Krill oil supplementation increases plasma concentrations of eicosapentaenoic and docosahexaenoic acids in overweight and obese men and women. Nutrition Research, 29, 609-615. http://dx.doi.org/10.1016/j.nutres.2009.09.004

Minami, M., Kimura, S., Endo T., Hamaue, N., Hirafuji, M., Togashi, H., Matsumoto, M., Yoshioka, M., Saito, H., Watanabe, S., Kobayashi, T. \& Okuyama, H. (1997). Dietary docosahexaenoic acid increases cerebral acetylcholine levels and improves passive avoidance performance in stroke-prone spontaneously hypertensive

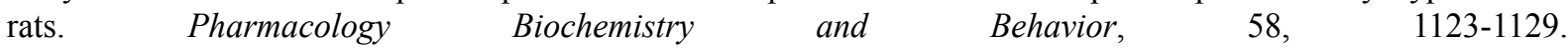
http://dx.doi.org/10.1016/S0091-3057(97)00300-6

Schmidt-Hieber, C., Jonas, P. \& Bischofberger, J. (2004). Enhanced synaptic plasticity in newly generated granule cells of the adult hippocampus. Nature, 429, 184-187. http://dx.doi.org/10.1038/nature02553

Song, H., Stevens, C. F. \& Gage, F. H. (2002). Neural stem cells from adult hippocampus develop essential properties of functional CNS neurons. Nature Neuroscience, 5, 438-445.

Song, C. \& Horrobin, D. (2004). Omega-3 fatty acid ethyl-eicosapentaenoate, but not soybean oil, attenuates memory impairment induced by central IL-1beta administration. Journal of Lipid Research, 45, 1112-1121. http://dx.doi.org/10.1194/jlr.M300526-JLR200 
Table 1. Ingredients and fatty acid composition of the F-1 diet

\begin{tabular}{|l|r|l|c|}
\hline & F-1 & Fatty acid & F-1 \\
\hline & $\mathrm{g} / \mathrm{kg}$ & & $\mathrm{g} / \mathrm{kg}$ \\
\hline Corn grain & 191 & Myristic acid (C14:0) & $0.9 \pm 0.9$ \\
\hline Wheat bran & 218 & Palmitic acid (C16:0) & $156 \pm 5.3$ \\
\hline Wheat flour & 358 & Palmitoleic acid [C17:1(n-7)] & ND \\
\hline Soybean meal & 80 & Stearic acid (C18:0) & $54.1 \pm 0.9$ \\
\hline Casein & 40 & Oleic acid [C18:1(n-9)] & $211 \pm 1.7$ \\
\hline Dry skim milk & 38 & Linoleic acid [C18:2(n-6)] & $524 \pm 8$ \\
\hline Soybean oil & 15 & Alpha-linolenic acid [C18:3(n-3)] & $44.9 \pm 1.3$ \\
\hline Mineral mixture & 10 & Arachidic acid (C20:0) & $1.4 \pm 0.9$ \\
\hline Vitamin mixture & 10 & Eicosenoic acid [C20:1(n-9)] & $3.3 \pm 1.3$ \\
\hline Amino acid mixture & 10 & Arachidonic acid [C20:4(n-6)] & ND \\
\hline DL-Methionine & 1 & Eicosapentaenoic acid [C20:5(n-3)] & $0.6 \pm 0.6$ \\
\hline Calcium carbonate & 9 & Docosapentaenoic acid [C22:5(n-3)] & ND \\
\hline & & Docosahexaenoic acid [C22:6(n-3)] & ND \\
\hline & & Lingoceric acid (C24:0) & $1.1 \pm 0.7$ \\
\hline
\end{tabular}

The F-1 standard diet, containing no fish products, comprised (g/100 g): protein, 21.3; fat, 5.1; fiber, 1; carbohydrate, 5; nonnitrogen, 57.5; and total energy, $17.7 \mathrm{~J} / \mathrm{g}$ and was purchased from Funabashi Farm, Chiba, Japan.

Values are means $\pm \mathrm{SEM}, n=4 ; \mathrm{ND}$, not detected.

Mineral mixture (g/kg) as formulated by Takeda Kagaku Shiryo, Tokyo, Japan: MnSO4, 15.7; FeSO4, 23.8; CoSO4, 0.7; CuSO4, 1.0; $\mathrm{Ca}(\mathrm{IO} 3)_{2}, 0.5 ; \mathrm{MgCO} 3,3.0 ; \mathrm{NaCl}, 300.0 ; \mathrm{CaCO} 3,655.3$.

Vitamin mixture $(\mathrm{g} / \mathrm{kg})$ as formulated by Takeda Kagaku Shiryo: retinal, $300 \mathrm{mg} / \mathrm{kg}$; vitamin D oil, $5 \mathrm{mg} / \mathrm{kg}$; DL- $\alpha$-tocopherol acetate, 5.0; menadione, 1.0; thiamine nitrate, 0.7; riboflavin, 0.8; pyridoxine hydrochloride, 1.0; nicotinamide, 4.0; calcium pantothenate, 1.7 ; choline chloride, 65.0 ; cyanocobalamin, 0.5 ; biotin, 0.015 ; saccharin sodium, 8.5; mil S- $\mathrm{Na}_{2}$ [natural flavor $(\mathrm{g} / 100 \mathrm{~g})$ : carbohydrate 8; protein 16; lactate 52; fat, 18.5], 100.0; glucose 90.0.

Amino acid mixture $(\mathrm{g} / \mathrm{kg})$ as formulated by Takeda Kagaku Shiryo: DL-methionine, 300.0; L-lysine hydrochloride, 300.0; defatted rice bran, 400.0 .

Table 2. Fatty acid composition of KPL

\begin{tabular}{|l|c|}
\hline Fatty acid & $\mathrm{mol} \%$ \\
\hline PLA & 31.5 \\
\hline OLA & 7.2 \\
\hline LA & 1.5 \\
\hline ALA & 1.3 \\
\hline AA & 0.3 \\
\hline EPA & 40.1 \\
\hline DPA & 0.4 \\
\hline DHA & 16.3 \\
\hline
\end{tabular}

PLA, palmitic acid (C16:0); STA, stearic acid (C18:0); OLA, oleic acid [C18:1(n-9)]; LA, linoleic acid [C18:2(n-6)]; ALA, alpha-linolenic acid [C18:3(n-3)]; AA, arachidonic acid [C20:4(n-6)]; EPA, eicosapentaenoic acid [C20:5(n-3)]; DPA, docosapentaenoic acid [C22:5(n-3)]; DHA, docosahexaenoic acid [C22:6(n-3)]. 
Table 3. Plasma fatty acid profiles in the control, LD, and HD groups

\begin{tabular}{|l|c|c|c|}
\hline & Control $(\mathrm{n}=15)$ & LD $(\mathrm{n}=14)$ & HD $(\mathrm{n}=13)$ \\
\hline & & $m o l \%$ & $28.05 \pm 0.16^{\mathrm{a}}$ \\
\hline PLA & $26.88 \pm 0.25^{\mathrm{b}}$ & $28.20 \pm 0.34^{\mathrm{a}}$ & $10.25 \pm 0.13^{\mathrm{b}}$ \\
\hline OLA & $12.65 \pm 0.19^{\mathrm{a}}$ & $10.49 \pm 0.17^{\mathrm{b}}$ & $10.81 \pm 0.16^{\mathrm{b}}$ \\
\hline LA & $11.93 \pm 0.30^{\mathrm{a}}$ & $11.65 \pm 0.34^{\mathrm{a}}$ & $15.14 \pm 0.35^{\mathrm{a}}$ \\
\hline ALA & $12.00 \pm 0.33^{\mathrm{b}}$ & $15.00 \pm 0.33^{\mathrm{a}}$ & $0.12 \pm 0.01$ \\
\hline AA & $0.10 \pm 0.02$ & $0.13 \pm 0.01$ & $12.75 \pm 0.33^{\mathrm{c}}$ \\
\hline EPA & $31.30 \pm 0.56^{\mathrm{a}}$ & $15.17 \pm 0.51^{\mathrm{b}}$ & $12.11 \pm 0.38^{\mathrm{a}}$ \\
\hline DPA & $0.35 \pm 0.02^{\mathrm{c}}$ & $8.65 \pm 0.20^{\mathrm{b}}$ & $1.92 \pm 0.06^{\mathrm{a}}$ \\
\hline DHA & $0.46 \pm 0.02^{\mathrm{b}}$ & $1.78 \pm 0.06^{\mathrm{a}}$ & $7.26 \pm 0.22^{\mathrm{a}}$ \\
\hline
\end{tabular}

Values are expressed as mean \pm S.E.M. Means in a row with superscripts without a common letter differ, $P<$ 0.05 .

Table 4. Major unsaturated fatty acid composition of the cerebral cortex and hippocampus in the control, LD, and HD groups

\begin{tabular}{|l|c|c|c|}
\hline & Control $(\mathrm{n}=11)$ & LD $(\mathrm{n}=14)$ & HD $(\mathrm{n}=10)$ \\
\hline Cerebral Cortex (mol\%) & & & \\
\hline AA & $11.71 \pm 0.22^{\mathrm{a}}$ & $10.82 \pm 0.22^{\mathrm{b}}$ & $10.15 \pm 0.26^{\mathrm{b}}$ \\
\hline EPA & $0.09 \pm 0.01^{\mathrm{c}}$ & $0.18 \pm 0.05^{\mathrm{b}}$ & $0.21 \pm 0.01^{\mathrm{a}}$ \\
\hline DPA & $0.14 \pm 0.02^{\mathrm{b}}$ & $0.37 \pm 0.01^{\mathrm{a}}$ & $0.41 \pm 0.01^{\mathrm{a}}$ \\
\hline DHA & $15.97 \pm 0.21^{\mathrm{b}}$ & $17.38 \pm 0.27^{\mathrm{a}}$ & $18.24 \pm 0.44^{\mathrm{a}}$ \\
\hline n-3/n-6 & $1.34 \pm 0.03^{\mathrm{c}}$ & $1.59 \pm 0.04^{\mathrm{b}}$ & $1.77 \pm 0.06^{\mathrm{a}}$ \\
\hline DHA/AA & $1.37 \pm 0.03^{\mathrm{c}}$ & $1.62 \pm 0.04^{\mathrm{b}}$ & $1.81 \pm 0.07^{\mathrm{a}}$ \\
\hline Hippocampus (mol\%) & & & \\
\hline AA & $13.19 \pm 0.31^{\mathrm{a}}$ & $11.90 \pm 0.18^{\mathrm{b}}$ & $10.74 \pm 0.45^{\mathrm{c}}$ \\
\hline EPA & $0.08 \pm 0.01^{\mathrm{c}}$ & $0.18 \pm 0.01^{\mathrm{b}}$ & $0.25 \pm 0.01^{\mathrm{a}}$ \\
\hline DPA & $0.046 \pm 0.01^{\mathrm{c}}$ & $0.27 \pm 0.01^{\mathrm{b}}$ & $0.38 \pm 0.03^{\mathrm{a}}$ \\
\hline DHA & $13.60 \pm 0.25^{\mathrm{b}}$ & $14.89 \pm 0.19^{\mathrm{a}}$ & $15.08 \pm 0.30^{\mathrm{a}}$ \\
\hline n-3/n-6 & $1.04 \pm 0.03^{\mathrm{b}}$ & $1.27 \pm 0.02^{\mathrm{a}}$ & $1.47 \pm 0.11^{\mathrm{a}}$ \\
\hline DHA/AA & $1.04 \pm 0.03^{\mathrm{b}}$ & $1.25 \pm 0.02^{\mathrm{a}}$ & $1.44 \pm 0.11^{\mathrm{a}}$ \\
\hline
\end{tabular}

Values are expressed as mean \pm S.E.M. Means in a row with superscripts without a common letter differ, $P<$ 0.05 .

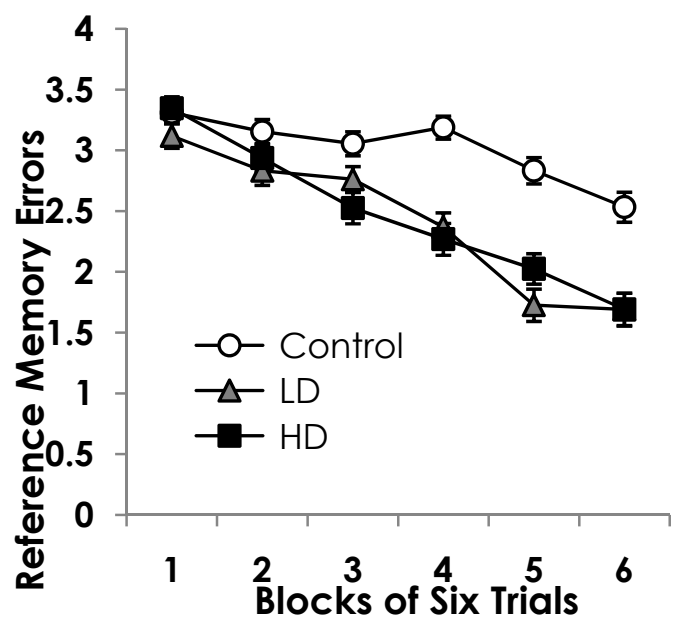

Figure 1a. Effect of chronic KPL administration on reference memory-related learning ability in the radial maze task. Control $(n=15), \operatorname{LD}(n=14), H D(n=13)$. Each value represents the number of RMEs as the mean $\pm S E M$ in each block of 6 trials 


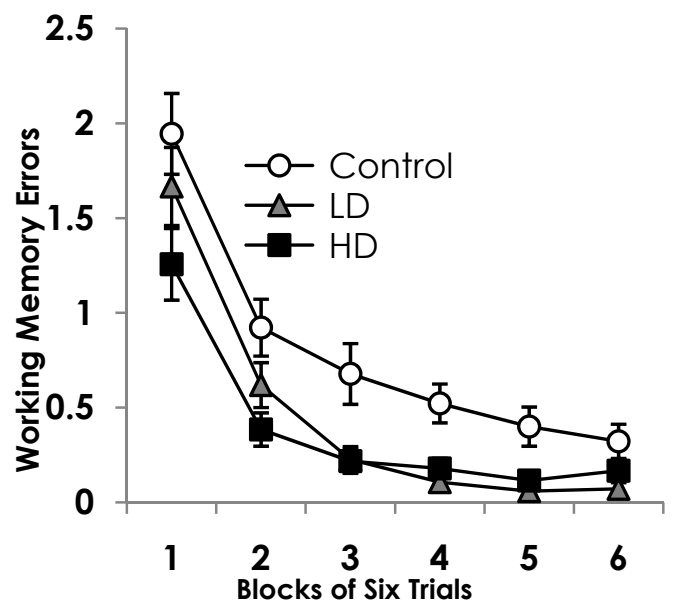

Figure 1b. Effect of chronic KPL administration on working memory-related learning ability in the radial maze task. Control $(n=15)$, LD $(n=14)$, HD $(n=13)$. Each value represents the number of RMEs as the mean \pm SEM in each block of 6 trials.

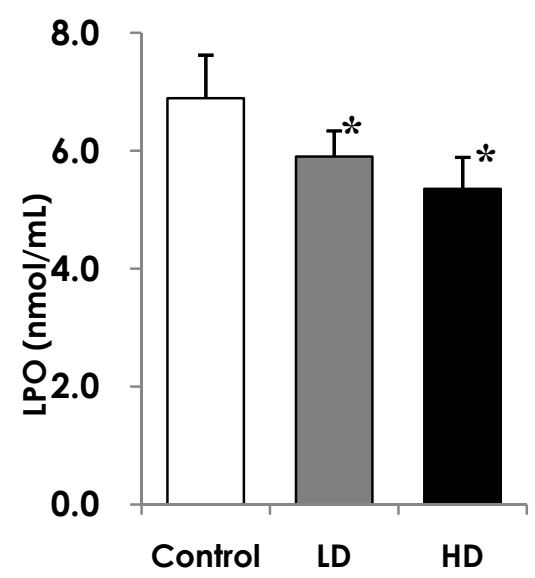

Figure 2. Effect of chronic KPL administration on plasma LPO levels. Data are expressed as the mean $\pm \mathrm{SEM}$ in each group. $* P<0.05$

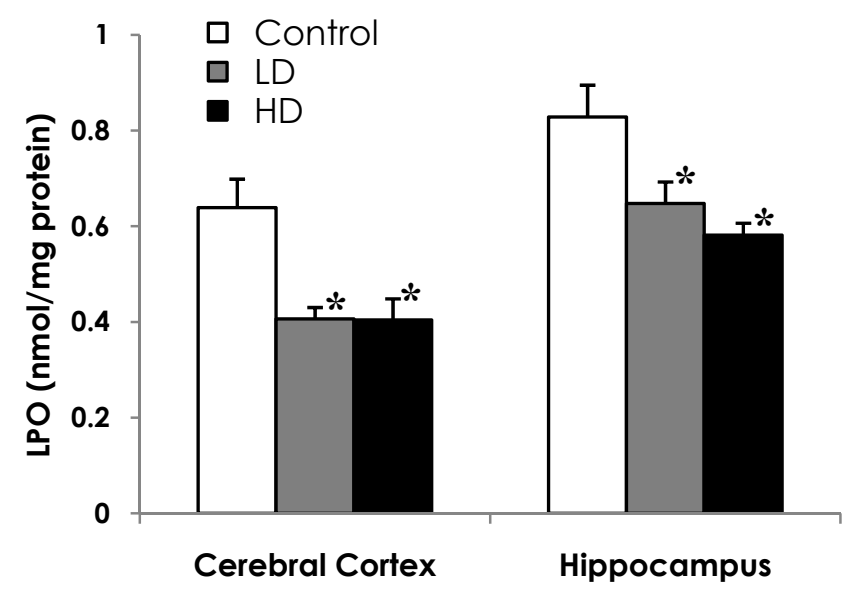

Figure 3a. Effect of chronic KPL administration on LPO levels in the cerebral cortex and hippocampus. Data are expressed as the mean $\pm \mathrm{SEM}$ in each group. $* P<0.05$. 


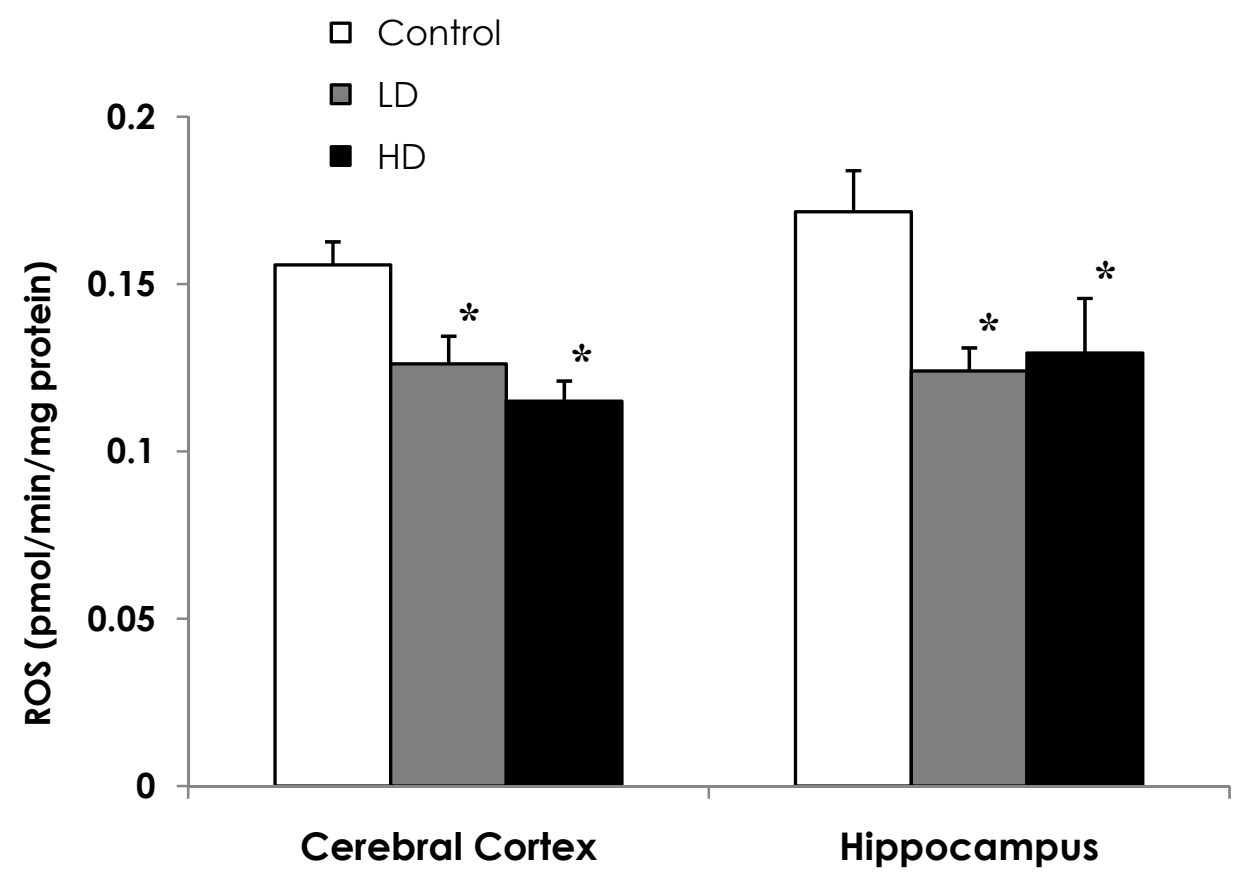

Figure 3b. Effect of chronic KPL administration on ROS levels in the cerebral cortex and hippocampus. Data are expressed as the mean \pm SEM in each group. ${ }^{*} P<0.05$

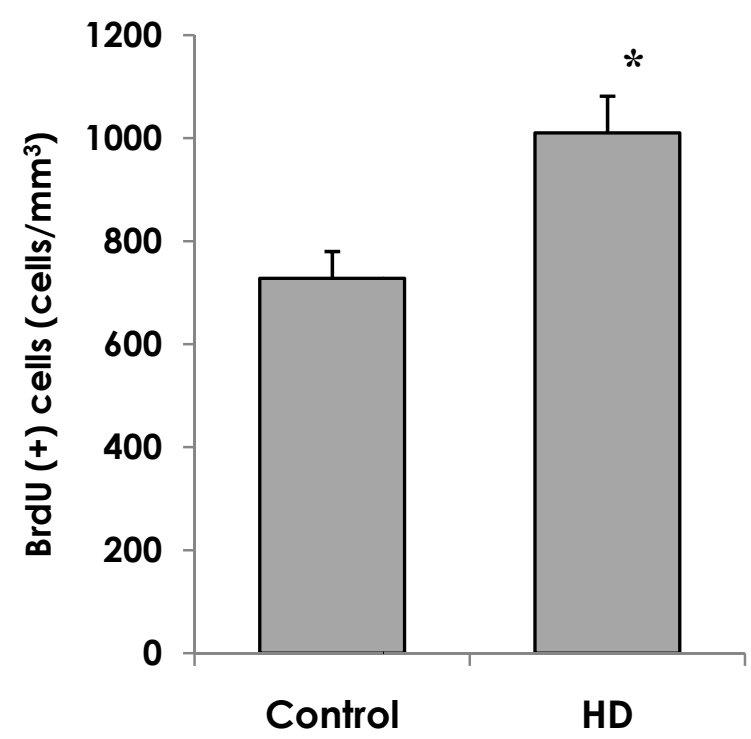

Figure 4. Effect of chronic KPL administration on the number of newly generated cells in the granule cell layer of the dentate gyrus. Control $(\mathrm{n}=4), \mathrm{HD}(\mathrm{n}=3)$. Each value represents the number of BrdU immunoreactive cells / volume of granule cell layer as the mean \pm SEM. $* P<0.05$ 